\title{
Chiral amino alcohols via catalytic enantioselective Petasis borono-Mannich reactions
}

John A. Kavouris ${ }^{1, \dagger}$, Kathryn E. Kavouris ${ }^{1, \dagger}$, Victor Wambua ${ }^{2}$, Roman Demerzhan ${ }^{1}$, Philip N. Moquist ${ }^{1}$, Mathew J. Vetticatt ${ }^{2, \star}$, and Scott E. Schaus ${ }^{1, \star}$

${ }^{1}$ Department of Chemistry and Center for Molecular Discovery (BU-CMD), Life Sciences and Engineering Building, Boston University

24 Cummington Mall, Boston, Massachusetts 02215, United States

${ }^{2}$ Department of Chemistry, Binghamton University

4400 Vestal Parkway East, PO Box 6000, Binghamton, New York 13902, United States

These authors contributed equally to this work

Chiral amino alcohols are valuable building blocks in the synthesis of drugs, natural products, and chiral ligands used in enantioselective catalysis. The Petasis borono-Mannich reaction is a multicomponent condensation reaction of aldehydes, amines, and boronic acids to afford chiral amines. This report describes a practical, easily scaled, enantioselective Petasis borono-Mannich reaction of glycolaldehyde, with primary or secondary amines, and boronates catalyzed by BINOLderived catalysts to afford chiral 1,2-amino alcohols in high yields and enantioselectivities. The reactions are executed at room temperature in ethanol or trifluorotoluene using commercially available reagents and leverage an inherently attractive feature of the multicomponent reaction; the ability to use amines and boronates that possess a wide range of structural and electronic properties. Computational modeling of the diastereomeric transition states using DFT calculations identified a non-conventional $\mathrm{CH}^{\cdots} \mathrm{O}$ interaction as a key feature that selectively stabilizes the transition state leading to the major enantiomer. The enantioselective catalytic reaction exemplifies a truly practical multicomponent condensation to afford 1,2-amino alcohols in highly enantioenriched form.

Enantioenriched chiral amino alcohols are used in the synthesis of natural products ${ }^{1}$, pharmaceutically active molecules ${ }^{2}$, and ligands employed in enantioselective catalysis ${ }^{3}$. Access to these valuable building blocks via enantioselective synthesis include the asymmetric aminohydroxylation, asymmetric ring opening of epoxides ${ }^{5}$ and aziridines ${ }^{6}$, the asymmetric amination of chiral enolates ${ }^{7}$, and nucleophilic addition to chiral imines ${ }^{8}$ (Fig. 1a). Notably, in the synthesis of vancomycin (Fig. 1c) and related natural products $^{9}$ Evans developed an asymmetric amination of oxazolidinones ${ }^{10}$, Nicolaou utilized the Sharpless asymmetric dihydroxylation subsequently converting the diol to the 1,2-amino alcohol ${ }^{11}$, and Boger elegantly implemented the Sharpless asymmetric aminohydroxylation ${ }^{12}$. Each of these methods were used to make key aryl glycines necessary for the route sought by each group. Another method to access chiral aryl glycinols is the nucleophilic addition of metal arenes to chiral imines best illustrated by use of the Ellman chiral sulfoxamine ${ }^{13}$. The need to access chiral aryl glycines and aryl glycinols is 
a

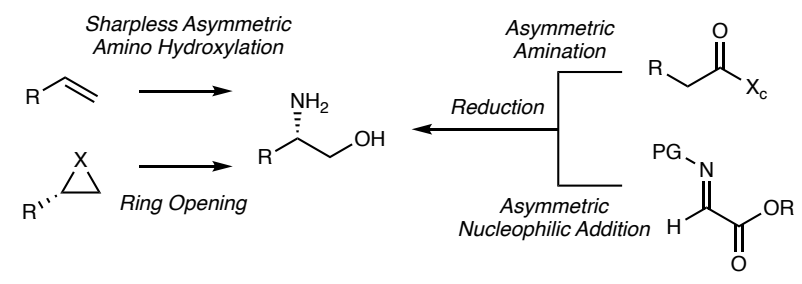

b

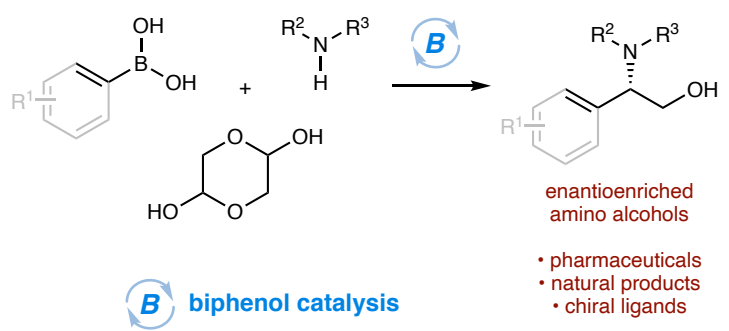

c

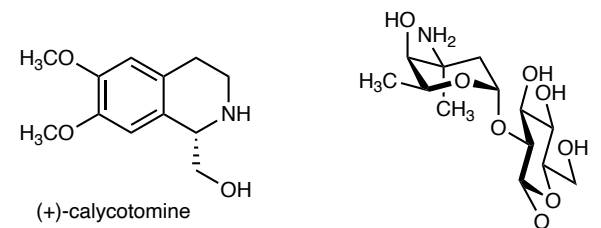

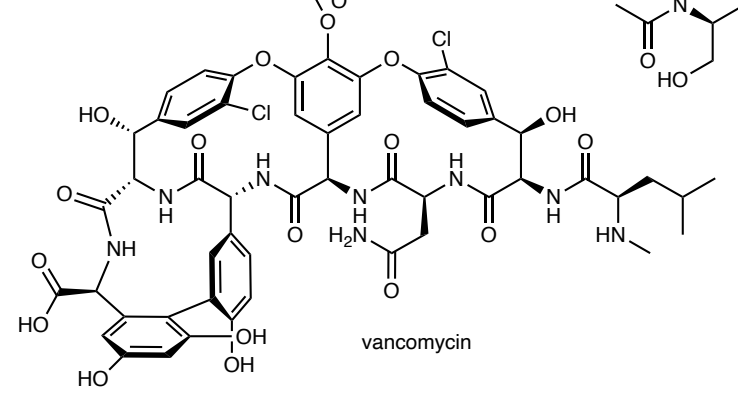

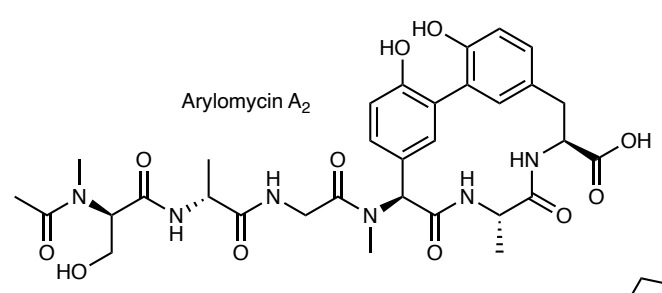

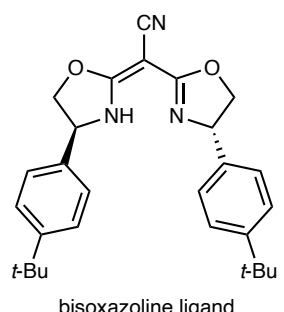

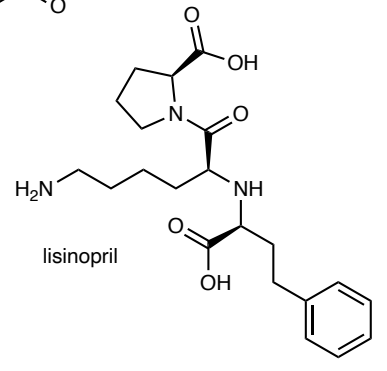

d<smiles>COc1ccc(B(O)c2ccccc2)cc1</smiles><smiles>COc1ccc([C@@H]([C@H](C)O)N(Cc2ccccc2)Cc2ccccc2)cc1</smiles>

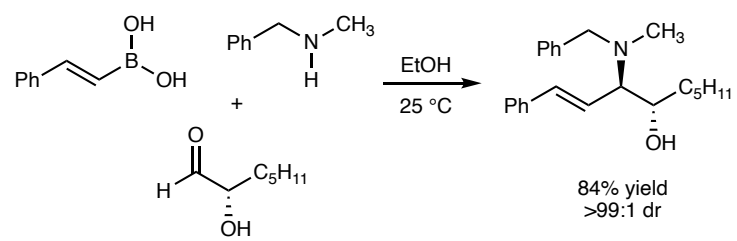<smiles>[R7]C=C[C@@H](CO)N([R])CCC(C)(C)C</smiles><smiles>OCCO</smiles><smiles>[3H]/C=C/B(O)OCC</smiles>

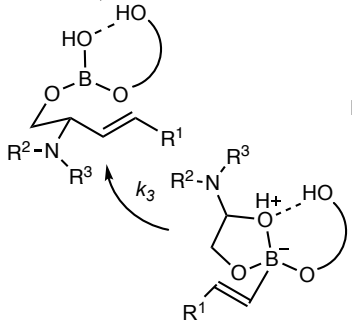<smiles></smiles>

f<smiles>COc1ccc(B(O)O)cc1</smiles>

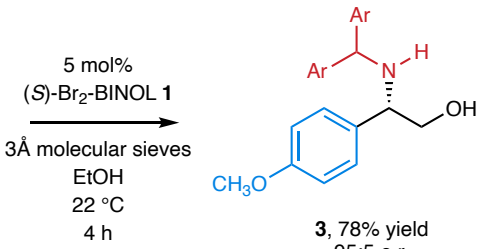<smiles>[R]c1cc2ccccc2c(-c2c(O)c([R])cc3ccccc23)c1O</smiles>

Figure 1 | Synthesis and utility of chiral 1,2-amino alcohols. a, Enantioselective synthesis of 1,2-amino alcohols. b, Asymmetric multi-component Petasis borono-Mannich reaction catalyzed by chiral biphenols. c, Natural products, pharmaceuticals, and chiral ligands that can be derived from chiral 1,2-amino alcohols. d, Substrate-directed Borono-Mannich reaction described by Petasis in 1998. e, Proposed catalytic cycle for enantioselective Petasis borono-Mannich reaction catalyzed by chiral biphenols. $\mathrm{f}$, Enantioselective multi-component Petasis borono-Mannich Reaction. e.r. = enantiomeric ratio. $\mathrm{Ar}=4-\mathrm{CH}_{3} \mathrm{OC}_{6} \mathrm{H}_{4} . \mathrm{Ph}=\mathrm{C}_{6} \mathrm{H}_{5} \cdot \mathrm{Bn}=\mathrm{C}_{6} \mathrm{H}_{5} \mathrm{CH}_{2}$. 
highlighted more recently in the syntheses of the arylomycins (Fig. 1c) by Dufour ${ }^{14}$, Smith and Heise at Genentech ${ }^{15}$, and by the Baran lab ${ }^{16}$. In each synthetic approach, a lengthy synthesis of a functionalized hydroxy aryl glycine suitable for use in the synthetic route was performed in multiple steps from the commercially available hydroxyphenyl glycine. Chiral aryl glycinols are also used for the synthesis of chiral bisoxazolines ${ }^{17}$ (Fig. 1c), a class of metal binding ligands widely employed in enantioselective catalysis and recently used by $\mathrm{Fu}$ and MacMillan in the development of an asymmetric alkylation of amino acids using photoredox and nickel catalysis ${ }^{18}$. These are just a few examples that illustrate the importance of amino alcohols in synthesis and provide an indication of the impact that a practical and scalable method for the synthesis of chiral 1,2-amino alcohols will have on different areas of synthesis.

In the 1990's Petasis reported the borono-Mannich reaction of alpha-hydroxy-aldehydes, amines, and boronic acids in a novel and interesting approach to provide access to chiral 1,2-amino alcohols ${ }^{19}$. The reaction was highly diastereoselective using chiral hydroxy aldehydes giving rise to stereochemically well-defined anti-1,2-amino alcohols (Fig. 1d). Since the initial reaction described by Petasis ${ }^{20}$, the reaction has been extensively used in synthesis ${ }^{21}$, however, an enantioselective version of the reaction has proved to be elusive 22 . In our continuing efforts to develop enantioselective boronate reactions catalyzed by ligand exchange we have described the enantioselective Petasis borono-Mannich reaction of ethyl glyoxylate with amines and vinyl boronic acids catalyzed by VAPOL ${ }^{23}$. While the reaction is one of the first examples of an enantioselective Petasis borono-Mannich reaction, the reaction was less than ideal for practical access to the chiral amino ester products requiring relatively high catalyst loadings at low temperatures. Given the value of chiral 1,2-amino alcohols as synthons, we sought to develop an enantioselective Petasis borono-Mannich reaction of achiral alpha-hydroxy aldehydes to afford amino alcohols $^{24}$ (Fig. 1b). We envisaged an enantioselective reaction of glycol aldehyde, amines, and boronates catalyzed by chiral biphenols; a mode of enantioselective boronate activation developed by us and others. Since our initial report, chiral biphenols have been used in enantio- and diastereoselective Petasis borono-Mannich reactions but in very specific contexts providing a narrow selection of building blocks afforded from the reaction ${ }^{25}$. In developing an enantioselective Petasis borono-Mannich reaction with glycol aldehyde we sought to leverage the ability to use different amine and boronate coupling partners to maximize the diversity of products afforded from the reaction; in so doing, developing an attractive method to provide access to valuable chiral synthons. Herein, we report a highly enantioselective Petasis borono-Mannich reaction affording chiral 1,2-amino alcohols under practical and operationally simple reaction conditions.

\section{Results and discussion}

Our experiments started by using diethyl boronate esters in the reaction with amines and glycol aldehyde dimer catalyzed by $(S)-3,3^{\prime}-B_{2}$-BINOL 1 . The reaction generally worked well for electron rich boronates affording the Mannich product in good yields and enantioselectivities. The drawback to using boronate esters in the reaction is the added synthetic step to first make the boronate ester from the corresponding commercially available boronic acid. We postulated that the reaction could be performed using the boronic acid in ethanol to facilitate the catalyst exchange process (Fig. 1e), both at the catalyst coordination step, but also at the end of the reaction to liberate the catalyst, a process we have 
Table 1 | Enantioselective Petasis Borono-Mannich Reaction in Ethanol

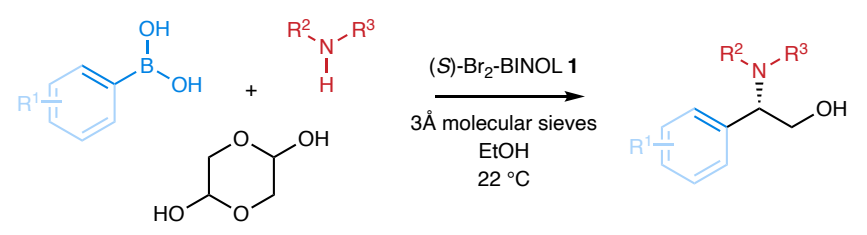<smiles>[Y]C([Al])N[C@@H](CO)c1ccc(OC)cc1</smiles>

3, $78 \%, 95: 5$ e.r.<smiles>OC[C@H](/C=C/c1ccsc1)NC([Al])[Al]</smiles>

8, 95\%, 97:3 e.r. a,c $^{\mathrm{c}}$<smiles>COc1ccc([C@@H](CO)N2CCOCC2)cc1</smiles>

13, $99 \%, 93: 7$ e.r. ${ }^{\text {a }}$

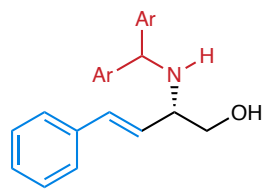

4, $93 \%, 92: 8$ e.r.

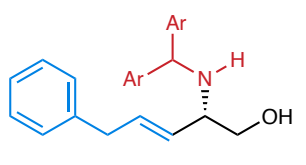

9, 82\%, 99:1 e.r.<smiles>COc1ccc(C(CO)N(Cc2ccccc2)Cc2ccccc2)cc1</smiles>

$14,80 \%, 93: 7$ e.r. ${ }^{\text {a }}$<smiles>OC[C@H](/C=C/c1ccc2ccccc2c1)NC([Al])[Al]</smiles>

5, 88\%, $97: 3$ e.r. ${ }^{\text {a,b }}$<smiles>COc1ccc([C@@H](CO)NC([Al])[Al])cc1OC</smiles>

10, $79 \%, 96: 4$ e.r. ${ }^{\mathrm{c}}$<smiles>COc1ccc([C@@H](CO)Nc2ccccc2Br)cc1</smiles>

$15,70 \%, 95: 5$ e.r.<smiles>[Y]C([Al])N([CH]CO)[C@H](/C=C/c1ccc(OC)cc1)CO</smiles>

6, $94 \%, 92: 8$ e.r. ${ }^{c}$<smiles>[Y]C([Al])NN(C)[C@H](CO)c1ccc2c(c1)OCO2</smiles>

11, $71 \%, 98: 2$ e.r.<smiles>COc1ccc([C@@H]([AlH2])N[AlH2])cc1</smiles>

16, $84 \%, 95: 5$ e.r.<smiles>[Y]C([Al])N[C@@H](/C=C/c1cccc(C(F)(F)F)c1)CO</smiles>

7, 62\%, 99:1 e.r. ${ }^{b}$

Boronic acid ( $1.3 \mathrm{mmol}, 1.3$ equiv), glycolaldehyde dimer ( $0.50 \mathrm{mmol}, 0.5$ equiv), amine (1.0 mmol, 1.0 equiv), ( $\mathrm{S}$ )- $\mathrm{Br}_{2}-\mathrm{BINOL} 1$ (0.05 mmol, 0.05 equiv), and $3 \AA$ molecular sieves $(500 \mathrm{mg})$ were added to a reaction flask with a stir bar. The mixture was suspended in $\mathrm{EtOH}(2.5 \mathrm{~mL})$ and stirred at room temperature for 16 hours. ${ }^{a} 0.10$ equiv 1 . ${ }^{b}$ Diethyl boronate was used in the reaction. ${ }^{\mathrm{C}} \mathrm{n} 1 \mathrm{~mL} \mathrm{EtOH}$. e.r. $=$ enantiomeric ratio. Ar $=4$ $\mathrm{CH}_{3} \mathrm{OC}_{6} \mathrm{H}_{4} \cdot \mathrm{Bn}=\mathrm{C}_{6} \mathrm{H}_{5} \mathrm{CH}_{2}$. 
demonstrated to be important in the overall catalytic cycle ${ }^{26}$. Indeed, by using molecular sieves in ethanol with para-methoxyphenyl boronic acid, catalytic (S)-3,3'-Br2-BINOL 1, glycol aldehyde dimer, and bis(4methoxyphenyl)methanamine, the corresponding 1,2-amino alcohol 3 was obtained in $78 \%$ isolated yield and 95:5 enantiomeric ratio (e.r.) at room temperature (Fig. 1f). The reaction conditions proved to be general for electron rich boronic acids with the benzhydryl amine (Table 1, amino alcohols 4 - 17). In some cases, higher catalyst loadings were required $(8,12,14,16)$, but still afforded the desired product in good yields ( $>50 \%$ yield) and high enantioselectivities ( $\geq 95: 5$ e.r.). An undesired pathway that can sometimes be a challenge in the Petasis borono-Mannich reaction is the direct Mannich product of the amine and aldehyde component; a competing pathway observed when using $2^{\circ}$-amines (dibenzylamine, 14) resulting in lower yields of the desired amino alcohol. The direct Mannich reaction pathway can be mitigated by using higher catalyst loadings, increasing the rate of the desired Petasis borono-Mannich reaction. In addition, the use of diethyl boronates in the reaction also increases the rate of the desired Petasis Mannich reaction affording the product in yields and selectivities commensurate with reactions using the boronic acid $(5,7,12)$. For electron rich, highly nucleophilic boronates reaction conditions were identified that afforded the enantioenriched 1,2-amino alcohols in high enantioselectivities.

Boronates possessing less nucleophilic character proved more challenging. The reactions would not proceed in ethanol. However, we knew that polar, aprotic, non-coordinating solvents serve as excellent reaction solvents for catalytic boronate reactions ${ }^{27}$. With this understanding of boronate reactivity in mind, we used a solvent mix of ethanol and trifluorotoluene that would facilitate the boronate-BINOL exchange process and promote the Mannich reaction. Trifluorotoluene is a more practical alternative to chlorinated solvents ${ }^{28}$, and while chloroform also works in the reaction, trifluorotoluene is preferred for reactions run in industrial settings ${ }^{29}$. The Petasis borono-Mannich reaction worked equally as well using a 10:1 mixture of trifluorotoluene:ethanol under the catalytic conditions (Table 2; amino alcohols 3, 4 \& 18) in comparison to using ethanol alone. This solvent mixture proved important for less reactive aryl boronic acids (Table 2; 20 - 25). The Mannich reactions worked equally as well using chloroform rather than trifluorotoluene, affording the desired amino alcohols in commensurate yields and enantioselectivities (Table 2; 20 - 23). The tert-butylphenyl boronic acid similarly performed well in the Mannich reaction with diallyl amine to afford the amino alcohol $\mathbf{2 6}$ in good isolated yields and enantioselectivities (96:4 e.r.). The Mannich reaction of $p$-benzyloxyphenyl boronic acid afforded the corresponding amino alcohol 27 in 96:4 e.r., a building block that could potentially be used in the synthesis of the arylomycins. The reaction of dimethoxyphenyl boronic acid with methylamino acetaldehyde dimethyl acetal afforded the corresponding amino alcohol 28 in excellent yields and good enantioselectivities, an amino alcohol used in the synthesis of (+)-calycotomine ${ }^{30}$ (Fig. 1c). The reaction proceeded well in both trifluorotoluene and chloroform ethanol mixtures. Lastly, we sought to evaluate the reaction using more functionalized boronic acid nucleophiles. The Mannich reaction of the Cbzprotected phenylalanine benzyl ester derived boronic acid with morpholine afforded the amino alcohol 29 in 93:7 diastereomeric ratio (d.r.) and 52\% isolated yield using trifluorotoluene and ethanol. The reaction in chloroform and ethanol resulted in a 9:1 d.r. and 68\% isolated yield. These results are notable given the existing stereocenter, albeit remote, and hydrogen bond donors and acceptors already present in the boronic acid nucleophile. In summary, the use of polar solvent mixtures of trifluorotoluene or 
Table 2 | Enantioselective Petasis Borono-Mannich Reaction

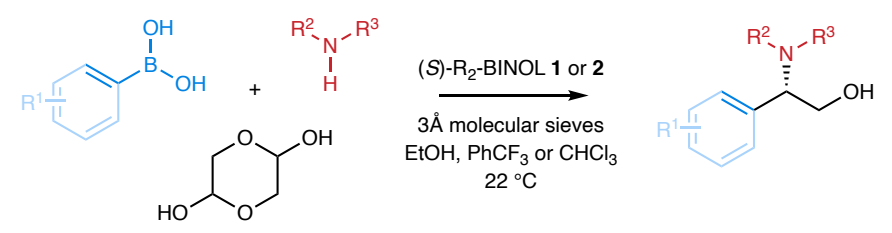

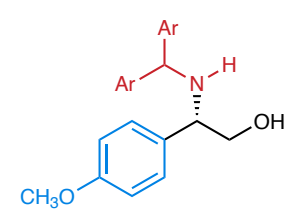

3, $75 \%, 96: 4$ e.r.

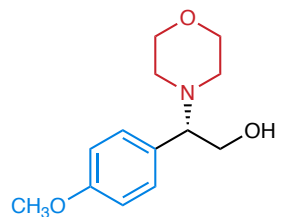

$13,89 \%, 96: 4$ e.r. $^{\text {a }}$

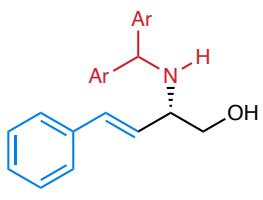

4, 90\%, 99:1 e.r. ${ }^{\mathrm{a}}$

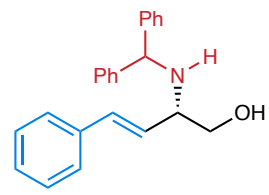

18, $86 \%, 99: 1$ e.r. $^{a}$

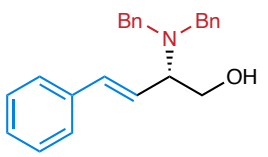

19, $90 \%, 97: 3$ e.r. $^{a}$<smiles>OC[C](c1ccccc1)N1CCOCC1</smiles>

$20,61 \%, 95: 5$ e.r. $^{\text {b }}$ $79 \%, 94: 6$ e.r.

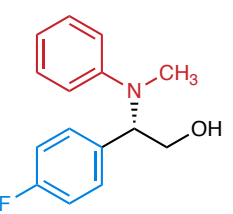

25, $78 \%, 98: 2$ e.r. ${ }^{\text {b,d }}$

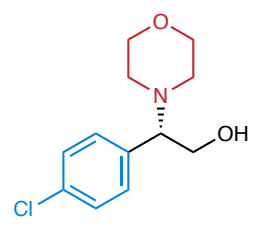

21, 65\%, 97:3 e.r. ${ }^{\text {b }}$ $71 \%, 97: 3$ e.r. ${ }^{\text {b,e }}$

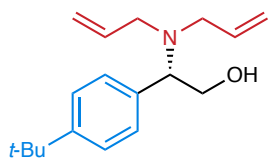

26, $70 \%, 96: 4$ e.r. . $^{\text {b. h h }}$<smiles>OC[C@H](c1ccc(Br)cc1)N1CCOCC1</smiles>

22, 58\%, 97:3 e.r. ${ }^{\text {b }}$ $80 \%, 97: 3$ e.r. ${ }^{\text {b,e }}$

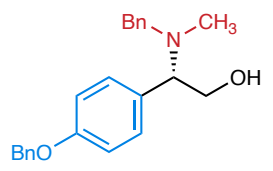

27, $84 \%, 96: 4$ e.r. ${ }^{\text {a,i }}$<smiles>OC[C@@H](c1ccc(F)cc1)N1CCOCC1</smiles>

23, $80 \%, 97: 3$ e.r. $^{\text {b }}$ $83 \%, 96: 4$ e.r.<smiles>COc1ccc([C@H](CO)N(C)CC(OC)OC)cc1OC</smiles>

28, 82\%, 95:5 e.r. a, $^{\text {h }}$ $95 \%, 93: 7$ e.r. ${ }^{a, h, k}$<smiles>OC[C@H](c1ccc(F)cc1)N(Cc1ccccc1)Cc1ccccc1</smiles>

24, 48\%, 99:1 e.r. . $^{\text {bc, d }}$

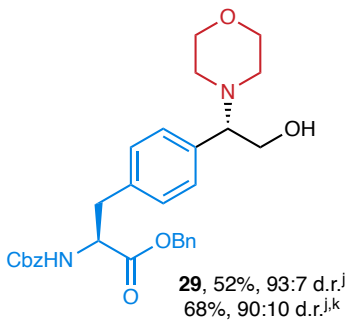

aBoronic acid ( $1.3 \mathrm{mmol}, 1.3$ equiv), glycolaldehyde dimer ( $0.50 \mathrm{mmol}, 0.5$ equiv), amine (1.0 mmol, 1.0 equiv), (S)-Br 2 -BINOL 1 (0.05 mmol, 0.05 equiv), and $3 \AA$ molecular sieves $(500 \mathrm{mg}$ ) were added to a reaction flask with a stir bar. The mixture was suspended in trifluorotoluene (2.2 $\mathrm{mL}$ ) and $\mathrm{EtOH}(0.3 \mathrm{~mL})$ and stirred at room temperature for 16 hours. ${ }^{\circ}$ Boronic acid ( $1.5 \mathrm{mmol}, 1.5$ equiv), glycolaldehyde dimer (1.0 mmol, 1.0 equiv), amine (1.0 mmol, 1.0 equiv), (S)-Ph - -BINOL 2 ( $0.15 \mathrm{mmol}, 0.15$ equiv), and $3 \AA$ molecular sieves (500 mg) were added to a reaction flask with a stir bar. The mixture was suspended in trifluorotoluene $(2.2 \mathrm{~mL})$ and $\mathrm{EtOH}(0.3 \mathrm{~mL})$ and stirred at room temperature for 2 hours. ${ }^{\mathrm{C}} \mathrm{Run}$ at $50{ }^{\circ} \mathrm{C}$. ${ }^{\mathrm{d}} \mathrm{Run}$

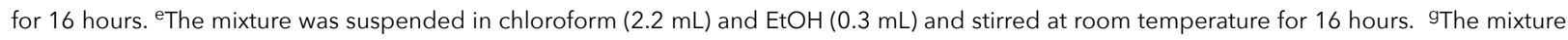
was suspended in trifluorotoluene $(1.8 \mathrm{~mL})$ and $\mathrm{EtOH}(0.7 \mathrm{~mL})$ and stirred from $0{ }^{\circ} \mathrm{C}$ to room temperature over 4 hours. ${ }^{\mathrm{h}} 0.07$ equiv 2 . i 0.12 equiv 1 for 4 hours. jBoronic acid $\left(0.2 \mathrm{mmol}, 1.3\right.$ equiv), glycolaldehyde dimer ( $0.17 \mathrm{mmol}, 1.0$ equiv), amine ( $0.17 \mathrm{mmol}, 1.0$ equiv), (S)-Ph ${ }_{2}$-BINOL 2 $(0.016 \mathrm{mmol}, 0.09$ equiv), and $3 \AA$ molecular sieves $(88 \mathrm{mg})$ were added to a reaction flask with a stir bar. The mixture was suspended in trifluorotoluene $(0.4 \mathrm{~mL})$ and $\mathrm{EtOH}(0.1 \mathrm{~mL})$ and stirred at room temperature for 16 hours. ${ }^{\mathrm{k}}$ Chloroform was used instead of trifluorotoluene. e.r. $=$ enantiomeric ratio. $\mathrm{Ar}=4-\mathrm{CH}_{3} \mathrm{OC}_{6} \mathrm{H}_{4} \cdot \mathrm{Ph}=\mathrm{C}_{6} \mathrm{H}_{5}$. $\mathrm{Bn}=\mathrm{C}_{6} \mathrm{H}_{5} \mathrm{CH}_{2}$. 
chloroform with ethanol enabled the use of less nucleophilic boronic acids in the asymmetric Petasis borono-Mannich reaction.

Computational modeling experiments were performed to evaluate the key factors mediating the observed selectivity. The enantioselectivity-determining step in the chiral biphenol catalyzed three component Petasis-borono-Mannich reaction of glycolaldeyde, morpholine, and p-methoxyboronic acid most likely proceeds via a tetracoordinate boronate intermediate ${ }^{31}$ formed by reaction of the iminium ion from condensation of morpholine and glycolaldehyde, $p$-methoxyboronic acid, and one of the hydroxyl groups of (S)-Br2-BINOL 1. We modeled the intramolecular transfer of the aryl group from the anionic boron to the iminium carbon of this intermediate using B97-D $32 / D e f 2-S V P^{33}$ calculations as executed in Gaussian ' $16^{34}$. Single-point energy calculations were performed using $\omega$ B97X-D ${ }^{35} /$ Def2-TZVP ${ }^{33}$ with a PCM solvent model $^{36}$ for ethanol for all computed transition structures (TS). Relative free energy barriers presented in the manuscript are extrapolated Gibbs free energies obtained by adding the free energy correction from the B97-D/Def2-SVP optimization to the high-level single point energy calculation. The free energies were corrected using Grimme's quasi rigid rotor-harmonic oscillator (qRRH) approach, which raises vibrational frequencies that are below $100 \mathrm{~cm}^{-1}$ to $100 \mathrm{~cm}^{-137}$.

The lowest energy TSs for aryl transfer from the boronate to either the re-face (R-TS) or the si-face (S-TS) of the iminium ion were identified after a rigorous conformational exploration (Fig. 2). Both TSs are characterized by (a) covalent attachment of the catalyst to boron via one of the phenolic oxygen atoms of catalyst, and (b) a strong intramolecular H-bonding interaction between the proton of the other phenolic group of the catalyst and an OH group attached to the boron (1.64 $\AA$ in $R$-TS and $1.62 \AA$ in $S$-TS). This intimate association of the catalyst to the reaction transition state allows for enantio-differentiation by distinctly different catalyst-substrate and substrate-substrate interactions. In the lowest energy TS leading to the $S$-enantiomer (S-TS), there is a moderately strong $\mathrm{CH} \cdots \mathrm{O}$ interaction $(2.27 \AA)$ between the iminium $\mathrm{CH}$ and the catalyst phenolic oxygen that is attached to the boron ${ }^{38}$. Additionally, there are two $\mathrm{CH}-\pi$ interactions between the protons $\alpha$ to the nitrogen in the morpholine ring and the $\pi$-system of the electron-rich migrating aryl anion $(2.59 \AA \text { and } 2.62 \AA \text { in S-TS })^{39}$. The transfer of the aryl group from boron to the iminium carbon occurs via a 5-membered envelope-like TS (S-TS, highlighted in green) with the migrating carbon atom representing the top of the envelope flap.

In contrast, the lowest-energy TS leading to the $R$-enantiomer ( $R$-TS) proceeds via a 5-membered envelope-like TS where the boron atom is at the top of the envelope flap. This conformation places the other four atoms of the envelope in a plane, resulting in destabilizing eclipsing interactions between the bulky morpholine substituent on the iminium carbon and the other substituents on the adjacent carbon atoms in the 5-membered TS (R-TS, highlighted in green). Intriguingly, both the $\mathrm{CH} \cdots \mathrm{O}$ and the $\mathrm{CH}_{-}$ $\pi$ interactions that stabilize $S$-TS (vide supra) are absent in $R$-TS. The only stabilizing interaction in $R$-TS is a weak non-covalent between the proton $\alpha$ to the nitrogen in the morpholine ring and the phenolic oxygen attached to the boron $(2.63 \AA)$. The forming C-C bond distance in R-TS is $2.17 \AA$, which corresponds to a later transition state than $S$-TS where the corresponding distance is $2.22 \AA$. The superior transition state stabilization of $S$-TS makes it $3.0 \mathrm{kcal} / \mathrm{mol}$ lower than $\boldsymbol{R}$-TS in free energy. This translates to a predicted enantiomeric ratio of $99.4: 0.6$ at $22{ }^{\circ} \mathrm{C}$, which is in reasonable agreement with experiment 

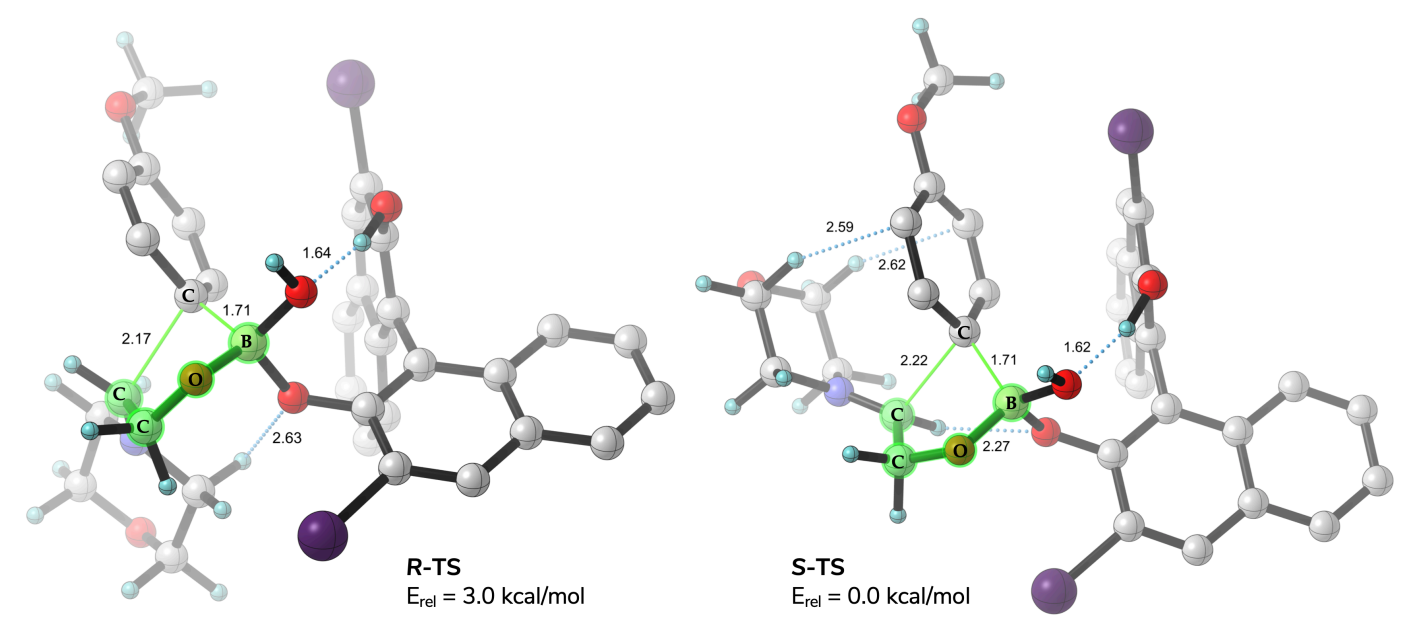

Figure 2 | Lowest energy transition structures leading to both enantiomers calculated using $\omega B$ 97X-D/Def2-TZVP PCM(ethanol)//B97-D/Def2-SVP level of theory. Transition state stabilization of $S$-TS makes it $3.0 \mathrm{kcal} / \mathrm{mol}$ lower that $R$-TS in free energy.<smiles>COc1ccc([C@@H](CO)NC([Al])[Al])cc1</smiles>

3, $96: 4$ e.r.

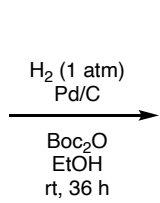

$\mathrm{t}, 36 \mathrm{~h}$

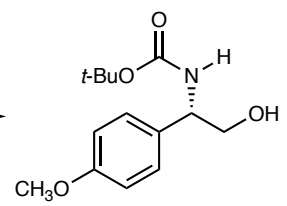

$30,69 \%, 96: 4$ e.r. b

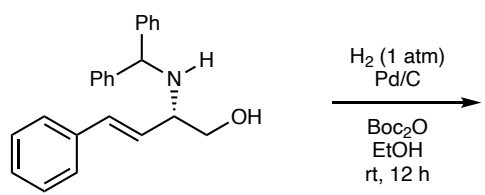

18, 99:1 e.r.

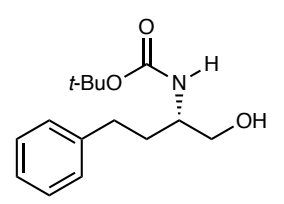

31, 95\%, 99:1 e.r.<smiles>C=CCN(CC=C)[C@@H](CO)c1ccc(C(C)(C)C)cc1</smiles>

25, $96: 4$ e.r.

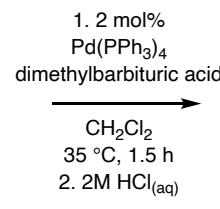

$t-\mathrm{Bu}$

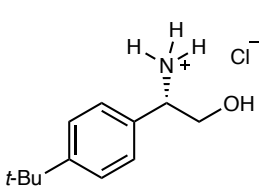

32, $99 \%$

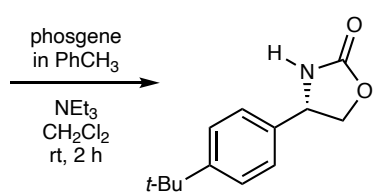

33, $90 \%, 96: 4$ e.r.

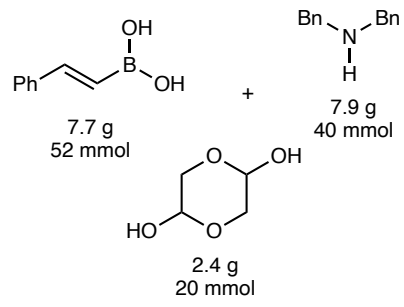

1. $3 \mathrm{~mol} \%$ (S) $-\mathrm{Br}_{2}-\mathrm{BINOL}$

3Å molecular sieves $\mathrm{PhCF}_{3}, \mathrm{EtOH}$

$22{ }^{\circ} \mathrm{C}, 2 \mathrm{~h}$

2. $2 \mathrm{M} \mathrm{NaOH}_{(\mathrm{aq})}$

3. Rochelle's salt $(\mathrm{aq})$

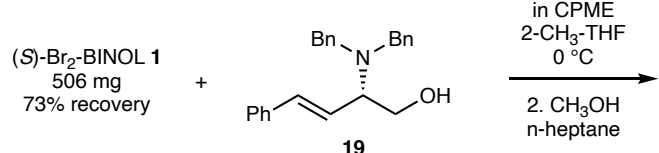

19<smiles>[BH2-][CH+]N(Cc1ccccc1)[C@@H](/C=C/c1ccccc1)CO</smiles>

$34,93 \%$ yield

$14.1 \mathrm{~g}$

$37 \mathrm{mmo}$

Figure 3 |a, One step diarlymethyl deprotection and Boc protection of 3 via palladium-catalyzed hydrogenation (5 mole \% Pd loading). b, One step benzhydryl deprotection, Boc reprotection, and olefin reduction of 18 using palladium-catalyzed hydrogenation at (5 mole \% Pd loading). c, Two step palladium-catalyzed allyl deprotection of $\mathbf{2 5}$ and subsequent synthesis of chiral oxazolidinone $\mathbf{3 3}$. $\mathrm{d}$, Extractive purification sequence for

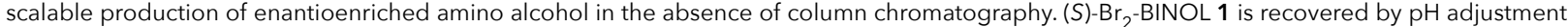
of an initial basic extraction followed by extraction of the $\mathrm{pH}$ adjusted aqueous layer. $\mathrm{Crude}^{19}$ was suspended in 2- $\mathrm{CH}_{3}-\mathrm{THF}_{\mathrm{H}}$ followed by treatment with $\mathrm{HCl}$, initially forming an amorphous solid precipitate. The amorphous solid was dissolved by the addition of methanol and a filterable solid was precipitated via a solvent exchange with n-heptane using rotary evaporation. e.r. $=$ enantiomeric ratio. $\mathrm{Ar}=4-\mathrm{CH}_{3} \mathrm{OC}{ }_{6} \mathrm{H}_{4} . \mathrm{Ph}=$ $\mathrm{C}_{6} \mathrm{H}_{5} \cdot \mathrm{Bn}=\mathrm{C}_{6} \mathrm{H}_{5} \mathrm{CH}_{2}$ 
(96:4 e.r. for 13). Finally, the $\Delta \mathrm{G}^{\ddagger}$ for $S$-TS is $19.2 \mathrm{kcal} / \mathrm{mol}$ with respect to separate starting materials - a value that is consistent with the facility of the reaction at $22{ }^{\circ} \mathrm{C}$.

The enantioenriched amino alcohol products of the Petasis Borono-Mannich reaction are readily manipulated as building blocks for use in synthesis (Fig. 3 a - c). The 4,4'-dimethoxydiphenylmethane group of amino alcohol 3 was selectively cleaved via palladium-catalyzed hydrogenolysis, and protected as the $t$-butylcarbamate in good yields $\left(30,69 \%\right.$ yield) using a one-pot procedure ${ }^{40}$. Similarly, amino alcohol 18 underwent olefin hydrogenation, benzhydryl hydrogenolysis, and $t$-butylcarbamate formation in excellent yields (31, 95\% yield). Hydrogenation of the olefin occurs rapidly, rendering an intermediate with the desired benzhydryl C-N bond to be cleaved by hydrogenolysis, ultimately resulting in facile removal of the benzhydryl group and formation of the carbamate. Palladium-mediated allyl deprotection ${ }^{41}$ of $\mathbf{2 5}$ proceeded in quantitative yields to afford $\mathbf{3 2}$ as the amine hydrochloride salt after workup (Fig. 3c). The salt was converted directly to the oxazolidone 33 in the presence of phosgene and amine base ${ }^{42}$. In each case, exposure to palladium did not racemize the benzylic or allylic amine stereocenter or otherwise degrade enantioenrichment.

We demonstrated the scalability of the method by running the reaction on a $40 \mathrm{mmol}$ scale, employing extractive purification techniques, and use of industrially appropriate solvents, ultimately minimizing the need for chromatographic separations (Fig. 3d). The Petasis borono-Mannich reaction chosen to illustrate the ability to produce multi-gram quantities of enantioenriched amino alcohols was the reaction of styrenylboronic acid and dibenzylamine with glycolaldehyde dimer. The reaction proceeded well using just 3 mole \% biphenol catalyst 1 and after filtration of the molecular sieves and dilution with 2$\mathrm{CH}_{3}$-THF, the catalyst and excess boronic acid were removed by aqueous $\mathrm{NaOH}$ extraction. Catalyst recovery was accomplished by adjusting the $\mathrm{pH}$ to 8 using aqueous $\mathrm{HCl}$ and extraction with tert-butyl methyl ether (TBME). The TBME extract was washed with aqueous Rochelle's salt to remove any remaining boronic acid. After concentration, a silica plug was used for final purification of the catalyst (73\% recovery). The 2- $\mathrm{CH}_{3}-\mathrm{THF}$ solution containing amino alcohol was dried and concentrated under reduced pressure to render crude 19 as a viscous oil. The freebase oil was suspended in 2- $\mathrm{CH}_{3}-\mathrm{THF}_{\mathrm{F}}$ and treated with dry $\mathrm{HCl}$ in cyclopentyl methyl ether (CPME) initially forming a white suspension that was brought into solution by the addition of anhydrous methanol. Solvent exchange with n-heptane was accomplished using rotary evaporation affording pure 34 as a solid (14.1 g, 93\% yield) recovered after filtration. The enantiomeric ratio of the recovered $\mathrm{HCl}$ salt was 97:3 demonstrating that the reaction can easily be scaled to multigram quantities without compromising the enantioselectivity of the reaction.

In summary, we have developed an enantioselective Petasis borono-Mannich reaction of glycol aldehyde, amines, boronic acids or boronate esters, catalyzed by chiral biphenols. The reaction is executed under ambient conditions using solvents easily amenable to academic and industrial settings. We ultimately worked to achieve a mix and stir procedure that readily provides access to valuable chiral building blocks in enantioenriched form. We were able to use electron deficient and electron rich boronates with $1^{\circ}, 2^{\circ}$, and aryl amines in an attempt to leverage the multi-component nature of the Petasis borono-Mannich reaction. Computational modeling of the diastereomeric transition states illustrates a two $\mathrm{CH}-\pi$ interactions between the moderately acidic protons $\alpha$ to the nitrogen in the morpholine ring 
and the $\pi$-system of the electron-rich migrating aryl anion leading to a preferred $S$-TS transition state 3.2 $\mathrm{kcal} / \mathrm{mol}$ lower than $\boldsymbol{R}$-TS in free energy. Finally, the reaction was scaled to afford multigram quantities of the enantioenriched amino alcohol product using an extractive workup procedure eliminating the need for column chromatography. Our hope is that the method will be used by the community as a practical method for accessing chiral amino alcohols for use as building blocks in synthesis.

\section{Dedication}

Dedicated to Professor Eric N. Jacobsen on the occasion of his $60^{\text {th }}$ birthday.

\section{Acknowledgements}

M.J.V. acknowledges NIH for support (R01 GM126283). M.J.V. also acknowledges support from the XSEDE Science Gateways Program (computational allocation ID CHE160009), which is supported by the National Science Foundation grant number ACI-1548562. S.E.S. acknowledges the NIH for support (R01 GM078240).

\section{Competing Interests}

The authors report no competing financial interests in connection with this research.

\section{Author Contributions}

J.A.K. and K.E.K. equally contributed to the experimental design and experimental execution. Preliminary experimental work was performed by R.D. and P.N.M. Computational experiments were performed by V.W.. M.J.V. designed computational experiments and wrote and participated in the preparation of the manuscript. S.E.S. designed experiments, wrote and coordinated the preparation of the manuscript.

Supplementary Information is available for this paper.

Correspondence and requests for materials should be addressed to Prof Matthew J. Vetticatt (vetticatt@binghamton.edu) and Prof Scott E.Schaus (seschaus@bu.edu).

\section{Current Affiliations}

Kathryn E. Kavouris, Ph.D.

kkavouris@syros.com

Syros Pharmaceuticals

35 CambridgePark Drive

Cambridge, MA 02140 
Philip N. Moquist, Ph.D.

pmoquist@seagen.com

Seattle Genetics, Inc.

21823 - 30th Drive S.E.

Bothell, WA 98021

Roman Demerzhan, M.S.

romand@runbox.com

IBM Flashsystems

10777 Westheimer, Suite 600

Houston, TX, 77042

1. Heravi, M. M., Lashaki, T. B., Fattahi, B. \& Zadsirjan, V. Application of asymmetric Sharpless aminohydroxylation in total synthesis of natural products and some synthetic complex bio-active molecules. RSC Adv. 8, 6634-6659 (2018).

2. Bergmeier, S. C. The Synthesis of Vicinal Amino Alcohols. Tetrahedron 56, 2561-2576 (2000).

3. Fache, F., Schulz, E., Tommasino, M. L. \& Lemaire, M. Nitrogen-Containing Ligands for Asymmetric Homogeneous and Heterogeneous Catalysis. Chem. Rev. 100, 2159-2232 (2000).

4. Li, G., Chang, H.-T., Sharpless, K. B. Catalytic Asymmetric Aminohydroxylation (AA) of Olefins. Angew. Chem., Int. Ed. Engl. 35, 451-454 (1996).

5. Weng, C., Zhang, H., Xiong, X., Lu, X., Zhou, Y. Evolution of Epoxides to Synthesize $\beta$-amino Alcohols: A Mini Review. Asian J. Chem. 26, 3761-3768 (2014).

6. Metro, T.-X., Duthion, B., Gomez Pardo, D., Cossy, J. Rearrangement of $\beta$-Amino Alcohols via Aziridiniums: a Review. Chem. Soc. Rev. 39, 89-102 (2010).

7. Evans, D. A., Britton, T. C., Ellman, J. A. \& Dorow, R. L. The asymmetric synthesis of $\alpha$-amino acids. Electrophilic azidation of chiral imide enolates, a practical approach to the synthesis of ( $r$ )- and ( $\left.s^{\prime}\right)$ - $\alpha$-azido carboxylic acids. J. Am. Chem. Soc. 112, 4011-4030 (1990).

8. Ferreira, F., Botuha, C., Chemla, F. \& Pérez-Luna, A. Tert-Butanesulfinimines: Structure, synthesis and synthetic applications. Chem. Soc. Rev. 38, 1162-1186 (2009).

9. Okano, A., Isley, N. A. \& Boger, D. L. Total Syntheses of Vancomycin-Related Glycopeptide Antibiotics and Key Analogues. Chem. Rev. 117, 11952-11993 (2017).

10. Evans, D. A., Dinsmore, C. J., Ratz, A. M., Evrard, D. A. \& Barrow, J. C. Synthesis and conformational properties of the M(4-6)(5-7) bicyclic tetrapeptide common to the vancomycin antibiotics. J. Am. Chem. Soc. 119, 3417-3418 (1997).

11. Nicolaou, K. C. et al. Total Synthesis of Vancomycin Aglycon-Part 1: Synthesis of Amino Acids 4-7 and Construction of the AB-COD Ring Skeleton. Angew. Chem., Int. Ed. Engl. 37, 2708-2714 (1998).

12. Boger, D. L. et al. Total Synthesis of the Teicoplanin Aglycon. J. Am. Chem. Soc. 122, 7416-7417 (2000).

13. Beenen, M. A., Weix, D. J. \& Ellman, J. A. Asymmetric synthesis of protected arylglycines by rhodium-catalyzed addition of arylboronic acids to N-tert-butanesulfinyl imino esters. J. Am. Chem. Soc. 128, 6304-6305 (2006).

14. Dufour, J., Neuville, L. \& Zhu, J. Intramolecular Suzuki-Miyaura reaction for the total synthesis of signal peptidase inhibitors, arylomycins A2and B2. Chem. - Eur. J. 16, 10523-10534 (2010).

15. Smith, P. A. et al. Optimized arylomycins are a new class of Gram-negative antibiotics. Nature 561, 189-194 (2018).

16. Peters, D. S., Romesberg, F. E. \& Baran, P. S. Scalable Access to Arylomycins via C-H Functionalization Logic. J. Am.

Chem. Soc. 140, 2072-2075 (2018).

17. Desimoni, G., Faita, G. \& Jørgensen, K. A. C2-symmetric chiral bis(oxazoline) ligands in asymmetric catalysis. Chem. Rev. 106, 3561-3651 (2006).

18. Zuo, Z. et al. Enantioselective Decarboxylative Arylation of $\alpha$-Amino Acids via the Merger of Photoredox and Nickel Catalysis. J. Am. Chem. Soc. 138, 1832-1835 (2016). 
19. Petasis, N. A. \& Zavialov, I. A. Highly Stereocontrolled One-Step Synthesis of anti- $\beta$-Amino Alcohols from Organoboronic Acids, Amines, and $\alpha$-Hydroxy Aldehydes. J. Am. Che. Soc. 120, 11798-11799 (1998).

20. Petasis, N. A. \& Akritopoulou, I. The boronic acid mannich reaction: A new method for the synthesis of geometrically pure allylamines. Tetetrahedron Lett. 34, 583-586 (1993).

21. Wu, P., Givskov, M. \& Nielsen, T. E. Reactivity and Synthetic Applications of Multicomponent Petasis Reactions. Chem. Rev. 119, 11245-11290 (2019).

22. Guerrera, C. A. \& Ryder, T. R. The Petasis Borono-Mannich Multicomponent Reaction. in ACS Symposium Series 1236 275-311 (2016).

23. Lou, S. \& Schaus, S. E. Asymmetric Petasis Reactions Catalyzed by Chiral Biphenols. J. Am. Chem. Soc. 130, 6922-3 (2008).

24. Muncipinto, G., Moquist, P. N., Schreiber, S. L. \& Schaus, S. E. Catalytic Diastereoselective Petasis Reactions. Angew. Chem., Int. Ed. Engl. 50, 8172-8175 (2011).

25. Han, W. Y., Wu, Z. J., Zhang, X. M. \& Yuan, W. C. Enantioselective organocatalytic three-component Petasis reaction among salicylaldehydes, amines, and organoboronic acids. Org. Lett. 14, 976-979 (2012).

26. Barnett, D. S., Moquist, P. N. \& Schaus, S. E. The mechanism and an improved asymmetric allylboration of ketones catalyzed by chiral biphenols. Angew. Chem., Int. Ed. Engl. 48, 8679-82 (2009).

27. Lou, S., Moquist, P. N. \& Schaus, S. E. Asymmetric allylboration of ketones catalyzed by chiral diols. J. Am. Chem. Soc. $128,12660-1(2006)$.

28. Prat, D. et al. Sanofi's Solvent Selection Guide: A Step Toward More Sustainable Processes. Org. Proc. Res. Dev. 17, 1517-1525 (2013).

29. Lienard, P., Gradoz, P., Greciet, H., Jegham, S. \& Legroux, D. Pilot scale process development of SL65.0102-10, an Ndiazabicyclo[2.2.2]-octylmethyl Benzamide. Org. Proc. Res. Dev. 21, 18-22 (2017).

30. D. Rozwadowska, M., Chrzanowska, M. \& Grajewska, A. Synthesis of Calycotomine and N-Methylcalycotomine Using a Petasis Reaction - Pomeranz-Fritsch-Bobbitt Cyclization Sequence. Heterocycles 86, 1119 (2012).

31. Tao, J. \& Li, S. Theoretical study on the mechanism of the Petasis-type boronic mannich reaction of organoboronic acids, amines, and $\alpha$-hydroxy aldehydes. Chin. J. Chem. 28, 41-49 (2010).

32. Becke, A. Density-Functional Thermochemistry. V. Systematic Optimization of Exchange-Correlation Functionals. J. Chem. Phys. 107, 8554-8560 (1997).

33. Weigend, F.; Ahlrichs, R. Balanced basis sets of split valence, triple zeta valence and quadruple zeta valence quality for $\mathrm{H}$ to Rn: Design and assessment of accuracy. Phys. Chem. Chem. Phys. 7, 3297-3305 (2005).

34. Gaussian 16, Revision C.01, Frisch, M. J. et al. Gaussian, Inc., Wallingford CT, 2016.

35. Chai, J. D.; Head-Gordon, M. Long-range corrected hybrid density functionals with damped atom-atom dispersion corrections. Phys. Chem. Chem. Phys. 10, 6615-20 (2008).

36. Amovilli, C. et al. Recent Advances in the Description of Solvent Effects with the Polarizable Continuum Model. Adv. Quant. Chem. 32, 227-261 (1998).

37. Grimme, S., Ehrlich, S. \& Goerigk, L. Effect of the damping function in dispersion corrected density functional theory. J. Comput. Chem. 32, 1456-1465 (2011).

38. Corey, E. J. \& Rohde, J. J. The application of the formyl C-H--O hydrogen bond postulate to the understanding of enantioselective reactions involving chiral boron Lewis acids and aldehydes. Tetrahedron Lett. 38, 37-40 (1997).

39. Neel, A. J., Hilton, M. J., Sigman, M. S. \& Toste, F. D. Exploiting non-covalent $\pi$ interactions for catalyst design. Nature 543, 637-646 (2017).

40. Poch, M., Alcón, M., Moyano, A., Pericàs, M. A. \& Riera, A. A short enantioselective synthesis of N-Boc- $\alpha$-amino acids from epoxy alcohols. Tet. Lett. 34, 7781-7784 (1993).

41. Garro-Helion, F., Merzouk, A. \& Guibé, F. Mild and Selective Palladium(0)-Catalyzed Deallylation of Allylic Amines. Allylamine and Diallylamine as Very Convenient Ammonia Equivalents for the Synthesis of Primary Amines. J. Org. Chem. 58, 6109-6113 (1993).

42. Noshita, M., Shimizu, Y., Morimoto, H. \& Ohshima, T. Diethylenetriamine-Mediated Direct Cleavage of Unactivated Carbamates and Ureas. Org. Lett. 18, 6062-6065 (2016). 